\title{
$\therefore$ \\ In Silico Screening of Phytochemicals of Styrax Benzoin Against the Inflammatory Mediators
}

$$
\begin{gathered}
\text { IJCRR } \\
\text { Section: Healthcare } \\
\text { ISI Impact Factor } \\
(2019-20): 1.628 \\
\text { IC Value (2019): } 90.81 \\
\text { SJIF (2020) = 7.893 } \\
\text { CC) @ @ } \\
\text { Copyright@IJCRR }
\end{gathered}
$$

\section{Swathy B ${ }^{1,2}$, Menaka M², Kiran G33, Prabhakar Reddy V1*}

\author{
'Department of Pharmaceutics, University College of Pharmaceutical Sciences, Palamuru University, Mahabubnagar-509oo1, Telangana, \\ India; 'Department of Pharmacy, Annamalai University, Chidambaram, Tamilnadu, India; ${ }^{3}$ School of Pharmacy, Anurag Group of Institu- \\ tions, Hyderabad-50o o88, Telangana, India.
}

\section{ABSTRACT}

Introduction: Inflammatory mediators are up-regulated during SARS-CoV-2 infection and also during injury and surgery. The wound is categorized as break down or opening of the skin, which could lead to malfunctioning of skin. Many physiological processes, protein targets, and cellular signalling pathways are involved in wound healing. Many inflammatory mediators are produced during injury and inhibition of the negative inflammatory mediators like 1RAK4 and NLRP3 inflammasome plays a key role in the wound healing process. Therefore, it could essential to find therapeutics for inhibiting the signalling pathways responsible for the release of negative inflammatory mediators. However, the conventional approaches to drug development are time-consuming and expensive.

Objective: In the present study, we have adopted a computational approach to identify lead molecules from Styrax Benzoinagainst the inflammatory mediators.

Method: We have screened ligands from Styrax Benzoin library for their ability to bind and inhibit the two potential inflammatory targets such as IRAK4 (Interleukin-1 Receptor Associated Kinase-4) with Protein Data Bank (6F3I) and innate immune signalling receptor NLRP3 (NOD-, LRR-, and pyrin domain-containing-3) inflammasome with Protein Data Bank (6NPY).

Results: We found that p-coumarin cinnamate 6 and coniferyl benzoate 12 could bind at the substrate-binding pocket of inflammatory targets with high binding affinity. Bioavailability properties and Pharmacophore features were also studied.

Conclusion: The results suggest that the Phytoconstituents of Styrax Benzoin have the potential to be developed as novel inhibitors of inflammatory mediators. These inflammatory mediators are upregulated during SARS-CoV-2 infections. However, their clinical usage on wound healing is a subject of further investigations and clinical trials.

Key Words: Styrax Benzoin, Inflammatory Mediators, SARS-CoV-2, Wound, 1RAK4, NLRP3 inflammasome

\section{INTRODUCTION}

Inflammatory mediators are upregulated during SARSCoV2 infections and also during injury and surgery. Viruses can affect the wound healing process by causing physiological changes. As per WHS (Wound Healing Society), a wound is categorized as break down or opening of the skin, which could lead to malfunctioning of skin. ${ }^{1}$ The physiology stages of wound healing are primary and secondary interventions, smaller wounds heal by primary interventions and larger wounds are heal by secondary interventions. ${ }^{2,3}$ Among the different stages in wound healing the first stage is the inflammatory stage and is a very essential phase in wound healing process. ${ }^{2,4}$. These clots release monocytes and forms macrophages and further produce the cytokines. ${ }^{5}$ When the tissue is an injury that going to release inflammatory cytokines from the damaged tissue cells. ${ }^{6,7}$ Neutrophils, also contribute to wound healing by releasing the cytokines and growth factors and also has phagocytosis functions which protect the wound against bacterial infections. ${ }^{8,9}$. Therefore, it could essential to find therapeutics for inhibiting the signalling pathways responsible for the release of negative inflammatory mediators. Inflammatory mediators like cytokines, chemokines and growth factors play the key role in wound healing by releasing fibroblasts and keratinocytes from cells and replace or restore the skin integrity. ${ }^{10,11}$ NLRP3 (Nod-like receptor protein) inflammasome cellular pathway is involved in wound healing and various inflammatory skin diseases. ${ }^{12,13}$ Yimin Chai group have studied the

\section{Corresponding Author:}

Dr. Prabhakar Reddy Veerareddy, University College of Pharmaceutical Sciences, Palamuru University, Mahabubnagar-509001, Telangana, India; Mobile: +91-998980499; E-mail: vpreddyindia@gmail.com

ISSN: $2231-2196$ (Print)

Received: 21.01 .2021
ISSN: 0975-5241 (Online)

Revised: 02.02 .2021
Accepted: 21.04 .2021
Published: 30.08 .2021 
role of NLRP3 expression in diabetic wounds in humans and the results demonstrate the higher expression of caspase1, NLRP3, IL-1 $\beta$ inflammatory mediators. ${ }^{14}$ These mediators could be the potential targets for the diabetic wound healing process. IRAK4 (interleukin-1 receptor-associated kinase 4) is an important molecular target for the release of inflammatory substances. ${ }^{15,16}$ IRAK inhibitors could be useful in the prophylaxis treatment of psoriasis, sclerosis, myocardial infarction, lupus erythematous, and arthritis. ${ }^{17,18}$

Styrax Benzoin (Latin: Benzoinum) is a balsamic resin and other species are Sumatra Benzoin and Siam Benzoin and belongs to the family Styraceae. ${ }^{19}$ It is grown high in tropical rain forests of South-Eastern Asia Countries like Indonesia, Thailand, China and Vietnam. (20) The plants grow up to $14 \mathrm{~cm}$ long and flowers are white in colour and bell-shaped. Sumatra benzoin resin contains chemical constituents are balsamic acid which esters of benzoic and cinnamic acids. ${ }^{21}$ They also contain Triterpenoid acids like summaresinolic and siaresinolic acids are present. ${ }^{22}$ Whereas, Siam Benzoin about $76 \%$ of coniferyl benzoate is present as the chief active constituent. ${ }^{23}$ The styrax benzoin resin is prepared as a tincture and used as an expectorant, carminative, disinfectant and diuretic. ${ }^{24-27}$ It also has biological uses in throat infection and upper respiratory tract infections. ${ }^{28}$ this study aims to investigate the In Silico computational study of 22 Phytoconstituents of Styrax Benzoin against the inflammatory mediators 1RAK4 and NLRP3 inflammasome.

\section{EXPERIMENTAL}

\section{Protein Preparation}

The present study is aimed to perform the computational studies of phytochemical analogues of Styrax Benzoin against COVID-19 negative immune regulators such as IRAK4 (Interleukin-1 Receptor Associated Kinase 4) with PDB ID: 6F3I and innate immune signaling receptor NLRP3 (NOD-, LRR-, and pyrin domain-containing 3) inflammasome with PDB ID: $6 \mathrm{NPY} .{ }^{29,30}$ The X-ray crystal structures of IRAK4 in complex with pyrrolotriazine inhibitor and NLRP3 bound to NEK7 were retrieved from Protein Data Bank (https://www.rcsb.org/structure/6F3I; https://www. rcsb.org/structure/6NPY). The protein targets were downloaded in PDB format and protein structural preparation in Macromolecule protocol was carried out in Discovery Studio software with default settings. Protein structures were cleaned and missing residues, Hydrogen's were added and $3 \mathrm{D}$ protonation was carried out to the target protein and minimized for the selected active residues.

\section{Ligand Preparation}

The important phytochemicals of Styrax Benzoin were collected from the literature survey and also from the TCIM database. The canonical smiles were saved in .csv format and structures were generated by using Data warrior software and all the 22 Phytoconstituents were saved in SD file. All the ligand structures were energy minimized using CHARMm force field in Small-molecule Protocol and different conformers were generated.

\section{Molecular Docking Studies}

Molecular docking was carried out for the 18 Phytoconstituents of Styrax Benzoin (1-22) to identify the molecular interactions between inflammatory targets 1RAK4 (PDB ID: 6F3I) and NLRP3 inflammasome (PDB ID: 6NPY). ${ }^{29,}{ }^{30} \mathrm{All}$ the ligands were docked with by using Accelrys Discovery Studio version 3.5 with Libdocker and CDocker software. The protein structures were retrieved from the protein data bank and the protein preparation and minimization were carried out with the default settings in Discovery Studio. The active site sphere is generated from ligand-binding sites with the current selection of Define and Edit Binding site in receptor-ligand Interaction tools. The binding site sphere specified based on the binding interactions of co-crystal ligand against the target protein, Docking Tolerance as 0.25, Docking Preferences as High Quality. The results were analysed and $3 \mathrm{D}$ and 2D interactions were obtained with Discovery Studio Visualizer.

\section{Pharmacophore Modelling}

Pharmacophores features are generated between receptorligand using Interaction Pharmcophore generations in DS Protocol. Different molecular interactions like HBA (hydrogen bond acceptor), HBD (hydrogen bond donor), HY (hydrophobic centre) and PI (Positive ionisable) were generated for the receptor-ligand complex. The study was done for the best-docked pose of p-coumaryl cinnamate 6 and coniferyl benzoate 12 for 1RAK4 and NLRP3 complex proteins.

\section{In Silico Absorption Distribution Metabolism Excretion (ADME) and Toxicity Prediction:}

All the Phytoconstituents of Styrax Benzoin(1-22) were predicted In silico ADME properties and Toxicity analysis were carried using Discovery Studio, pKCSM web server and Data Warrior Software. ${ }^{31,32}$

\section{RESULTS AND DISCUSSION}

\section{Molecular Docking Studies}

The molecular docking studies were carried out in Discovery Studio Docking software. The 3-dimensional proteins (PDB: $6 \mathrm{~F} 3 \mathrm{I}$ and $6 \mathrm{NPY}$ ) were retrieved from the protein data bank. All the proteins were prepared and their energies were minimized by the protein preparation wizard. The receptor sphere around their co-crystal ligands was generated using the current 
selection of co-crystal ligand interactions. All the selected 22 Phytoconstituents of Styrax Benzoinwere downloaded from Pubmed (Figure-1). The molecular docking using normal mode was carried out and results were analysed.

The initial rationale molecular docking studies of all 22 Phytoconstituents of Styrax Benzoin (1-22) in the active site of
1RAK4 (PDB ID: 6F3I) and NLRP3 inflammasome (PDB ID: 6NPY)were carried out in order to predict the binding efficiencies. The molecular docking scores are summarized in (Table:1-3). Initially the docking studies were carried out for all ligands with Libdock which High Throughput Screen based software and best ligand poses were further docked with CDocker.

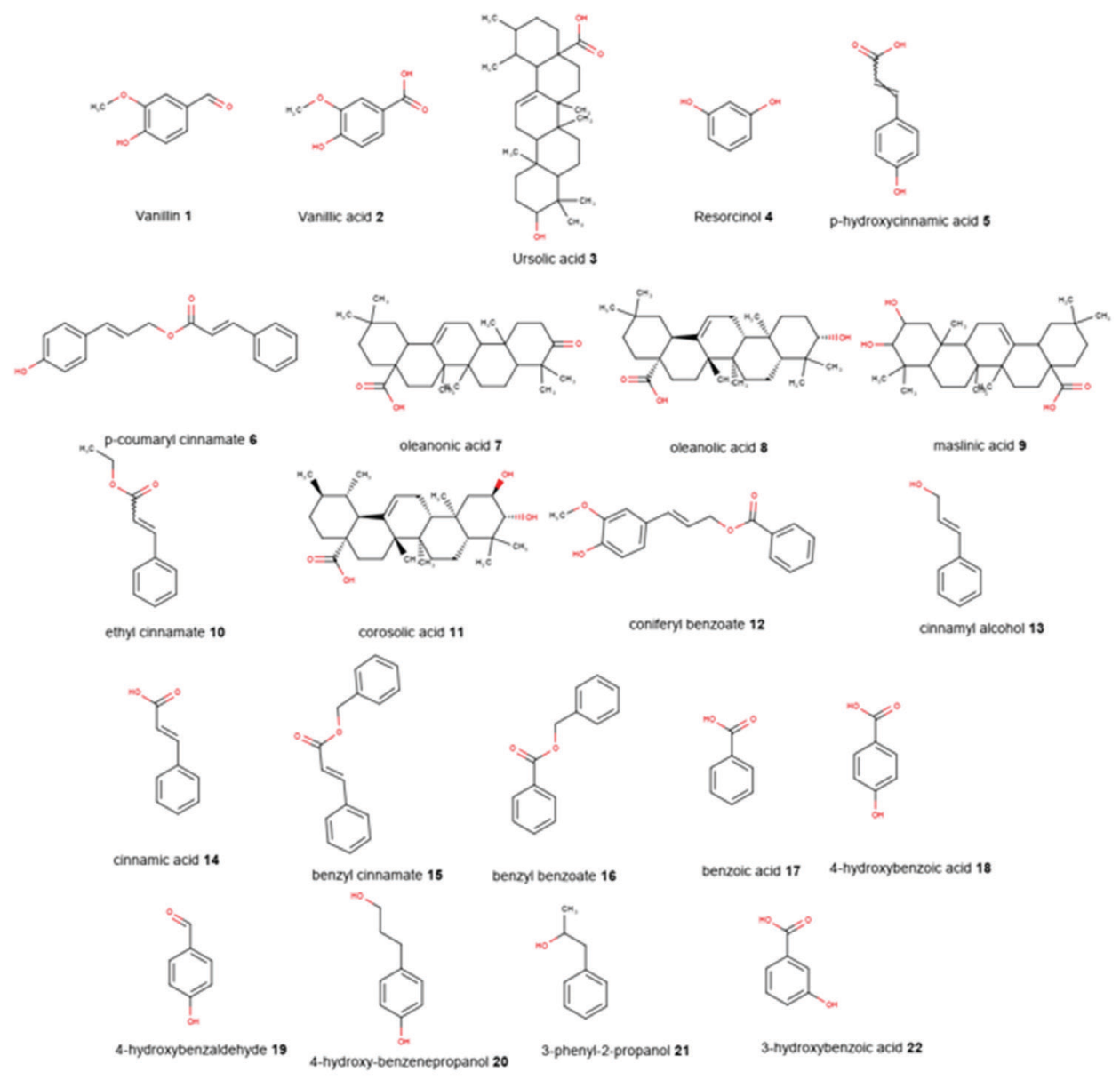

Figure 1: 2D Structures of Phytoconstituents of Styrax Benzoin.

Table 1: Docking studies of 22 Phytoconstituents of Styrax Benzoin against 1RAK4 and NLRP3 inflammasome

\begin{tabular}{llcc} 
Compd ID & Phytochemical & \multicolumn{2}{c}{ Libdock Score } \\
Panillin & PDB ID: 6F3I & 58.67 \\
2 & vanillic acid & 61.92 & 66.44 \\
3 & ursolic acid & 66.13 & 98.70 \\
4 & resorcinol & 46.36 & 73.72 \\
5 & p-hydroxycinnamic acid & 73.01 & 118.76 \\
6 & p-coumaryl cinnamate & 105.19 & -- \\
7 & oleanonic acid & 102.59 & -- \\
8 & oleanolic acid & 104.27 & --
\end{tabular}


Table 1: (Continued)

\begin{tabular}{llcc} 
Compd ID & Phytochemical & \multicolumn{2}{c}{ Libdock Score } \\
& & PDB ID: 6F3I & PDB ID: 6NPY \\
\hline 10 & ethyl cinnamate & 76.38 & 83.74 \\
11 & corosolic acid & 98.18 & -- \\
12 & coniferyl benzoate & 99.36 & 119.99 \\
13 & cinnamyl alcohol & 63.15 & 74.23 \\
14 & cinnamic acid & 68.01 & 68.64 \\
15 & benzyl cinnamate & 97.90 & 104.39 \\
16 & benzyl benzoate & 82.65 & 104.26 \\
17 & benzoic acid & 52.48 & 58.61 \\
18 & 4-hydroxybenzoic acid & 59.47 & 58.56 \\
19 & 4-hydroxybenzaldehyde & 55.62 & -- \\
20 & 4-hydroxy-benzenepropanol & 66.75 & -- \\
21 & 3-phenyl-2-propanol & 62.01 & 75.71 \\
22 & 3-hydroxybenzoic acid & 58.50 & 73.47 \\
23 & Co-Crystal Ligand & $130.28(\mathrm{CKN})$ & -- \\
\hline
\end{tabular}

Table 2: Docking studies of Phytoconstituents of Styrax Benzoin against 1RAK4 (PDB ID: 6F3I)

\begin{tabular}{|c|c|c|c|c|c|c|}
\hline S. No & Compd Id & Phytochemical & Cdocker Energy & $\begin{array}{l}\text { Binding Energy } \\
(\mathrm{kcal} / \mathrm{mol})\end{array}$ & H-Bond & Hydrophobic \\
\hline 1 & 3 & ursolic acid & -94.22 & $-43 \cdot 44$ & $\operatorname{Ser} 269(2.33)$ & Val2oo, Ala315, Leu318 \\
\hline 2 & 6 & $\begin{array}{l}\text { p-coumaryl cin- } \\
\text { namate }\end{array}$ & 20.90 & -36.49 & $\begin{array}{l}\text { Met265(2.01), } \\
\text { Asn316(2.23), } \\
\text { Tyr264(2.86) }\end{array}$ & $\begin{array}{l}\text { Val20o, Ala211, Leu318, } \\
\text { Met192 }\end{array}$ \\
\hline 3 & 8 & oleanolic acid & -61.84 & -48.08 & Asp272(2.51) & $\begin{array}{l}\text { Val20o, Ala211, Lys213, } \\
\text { Ala315, Leu318, Tyr262 }\end{array}$ \\
\hline 4 & 9 & maslinic acid & -90.53 & -58.59 & $\begin{array}{l}\operatorname{Arg}_{273}(2.46) \\
\operatorname{Asp278(1.94)}\end{array}$ & Met192, Ala315, Val2oo \\
\hline 5 & 11 & corosolic acid & $-93 \cdot 77$ & $-37 \cdot 44$ & $\begin{array}{l}\text { Glu194(2.99), } \\
\text { Asp272(2.82), } \\
\text { Gly193(2.72) }\end{array}$ & Ala315 \\
\hline 6 & 12 & coniferyl benzoate & 20.73 & -78.73 & $\begin{array}{l}\text { Glu194(2.43), } \\
\text { Met265(1.91), } \\
\text { Val263(2.84) } \\
\text { Tyr264(2.63) }\end{array}$ & $\begin{array}{l}\text { Val2oo, Met192, Tyr262, } \\
\text { Ala211, Leu318 }\end{array}$ \\
\hline 7 & 15 & benzyl cinnamate & 25.53 & -48.77 & -- & Met192, Val2oo, Ala211 \\
\hline 8 & & CKN & 30.24 & -82.794 & $\begin{array}{l}\operatorname{Arg}_{273}(1.87), \\
\operatorname{Arg} 273(2.88), \\
\operatorname{Asn} 316(2.38), \\
\operatorname{Asp329}(2.48), \\
\operatorname{Asp272}(2.81), \\
\operatorname{Asp272}(2.37),\end{array}$ & $\begin{array}{l}\text { Met192, Val2oo, Lys213, } \\
\text { Ala211, Val246, Met265, } \\
\text { Leu318, }\end{array}$ \\
\hline
\end{tabular}


Table 3: Docking studies of Phytoconstituents of Styrax Benzoin against NLRP 3 inflammasome (PDB ID: 6NPY)

\begin{tabular}{|c|c|c|c|c|c|}
\hline $\begin{array}{l}\text { Compd } \\
\text { ID }\end{array}$ & Phytochemical & $\begin{array}{l}\text { Cdocker } \\
\text { Energy }\end{array}$ & $\begin{array}{l}\text { Binding } \\
\text { Energy }\end{array}$ & H-Bond & Hydrophobic \\
\hline 1 & vanillin & 21.95 & -32.55 & $\begin{array}{l}\operatorname{Arg}_{165}(2.02), \operatorname{Arg}_{165}(2.39) \\
\operatorname{Gly227}(2.93), \operatorname{Ile2228(2.84)}\end{array}$ & $\begin{array}{l}\text { Leu169, Ile232, Pro410, } \\
\text { Ile232, }\end{array}$ \\
\hline 2 & vanillic acid & $25 \cdot 54$ & -28.63 & $\begin{array}{l}\operatorname{Arg}_{165}(2.20), \operatorname{Arg}_{165}(2.10), \\
\operatorname{Arg}_{165}(2.08), \operatorname{Gly}_{22}(3.00), \\
\operatorname{Ile228}_{2}(2.70)\end{array}$ & $\begin{array}{l}\text { Pro410, Leu169, Ile232, } \\
\text { Leu411 }\end{array}$ \\
\hline 5 & $\begin{array}{l}\text { p-hydroxy cinnamic } \\
\text { acid }\end{array}$ & 26.17 & $-43 \cdot 32$ & $\begin{array}{l}\operatorname{Arg}_{165}(1.97), \operatorname{Arg}_{165}(1.92), \\
\operatorname{His}_{220}(2.24), \operatorname{Arg} 165(2.12) \\
\operatorname{Gly}_{227}(1.89), \operatorname{His}_{520}(3.00)\end{array}$ & Ile232, Pro410, Leu411 \\
\hline 6 & $\begin{array}{l}\text { p-coumaryl cin- } \\
\text { namate }\end{array}$ & 29.03 & $-67 \cdot 33$ & $\begin{array}{l}\text { Thr167(1.98), His520(2.17), } \\
\text { Thr167(2.02), Gly229(2.41) }\end{array}$ & Pro410, Ile232, Arg235 \\
\hline 10 & ethyl cinnamate & 24.03 & -20.59 & $\operatorname{Arg}_{165}(1.92), \operatorname{His}_{520}(2.24)$ & Ile232, Pro410, \\
\hline 12 & coniferyl benzoate & $27 \cdot 54$ & -63.66 & $\begin{array}{l}\text { Thr167(2.22), Thri67(3.03), } \\
\operatorname{Arg} 165(2.40), \operatorname{Gly} 229(2.45) \text {, } \\
\text { Gly227(2.95), }\end{array}$ & $\begin{array}{l}\text { Phe371, Pro410, Ile232, } \\
\text { Leu411, Leu162 }\end{array}$ \\
\hline 13 & cinnamyl alcohol & 11.55 & -22.19 & $\operatorname{Arg}_{165}(1.78)$ & Leu169, Ile232, Pro410, \\
\hline 14 & cinnamic acid & 21.16 & -38.80 & Thr167(2.24), Thr167(1.98) & Ile232, Pro410, \\
\hline 15 & benzyl cinnamate & 28.74 & -36.94 & $\operatorname{Arg}_{165}(2.00), \operatorname{Arg}_{165}(2.81)$ & $\begin{array}{l}\text { Trp414, Leu169, Ile232, } \\
\text { Pro410 }\end{array}$ \\
\hline 16 & benzyl benzoate & 26.25 & -46.00 & Gly229(2.68), Gly229(2.94) & Trp414,Ile232, Leu411 \\
\hline 17 & benzoic acid & 18.05 & -20.75 & Thrı67(1.87), Thrı67(1.97) & Phe371, Ile232, Pro410 \\
\hline 18 & $\begin{array}{l}\text { 4-hydroxybenzoic } \\
\text { acid }\end{array}$ & 21.77 & $-49 \cdot 46$ & $\begin{array}{l}\text { Thr167(1.97), Gly227(2.69), } \\
\text { Thr167(1.92), Gly229(2.50) }\end{array}$ & Ile232, Pro410 \\
\hline 20 & $\begin{array}{l}\text { 4-hydroxy-benzene- } \\
\text { propanol }\end{array}$ & 25.21 & -41.72 & 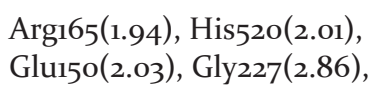 & Trp414, Leu162, Ile232 \\
\hline 21 & $\begin{array}{l}\text { 3-phenyl-2-pro- } \\
\text { panol }\end{array}$ & 20.96 & -26.35 & Gly227(2.12), Gly229(2.67) & Trp414, Ile232 \\
\hline 23 & ADP & 40.39 & -16.58 & $\begin{array}{l}\text { Thr167(3.01), Tyr379(2.95), } \\
\text { Thr167(2.70), Arg165(2.82), } \\
\text { Pro410(2.90), Ile519(3.33), } \\
\text { His520(3.77), }\end{array}$ & Ile232, Trp414 \\
\hline
\end{tabular}

Molecular Docking Studies with 1RAK4 (PDB ID: 6F3I):

The molecular docking study was carried out for 22 phytoconstituents of Styrax Benzoin (1-22) into the active site of 1RAK4 (PDB ID: 6F3I). IRAK family (IRAK1-4) plays a central role in positive and negative inflammatory responses by regulating the expression of genes in immune cells. ${ }^{33}$ These signals which stimulus the various inflammatory mediators and plays a key role for elimination of pathogens like virus, bacteria and carcinogenic cells, as well as for wound healing.

Among the ligands docked against IRAK-4, coniferyl benzoate (12) has shown excellent free energy binding with a Lib dock score of 99.36 and with Cdock score of -20.73 and with a binding energy value of $-78.73 \mathrm{kcal} / \mathrm{mol}$. Coniferyl benzoate(12) exerted $\mathrm{H}$-bond interactions and bond distance in $\AA$ with Glu194(2.43), Met265(1.91), Val263(2.84)
Tyr264(2.63) amino acid residues and hydrophobic interactions with Val200, Met192, Tyr262, Ala211, Leu318 residues. Similarly, p-coumaryl cinnamate has exhibited H-bond interactions with Met265(2.01), Asn316(2.23), Tyr264(2.86) residues and hydrophobic interactions with Val200, Ala211, Leu318, Met192 amino acid residues with Libdock Score 105.19and Cdock score -20.90and binding energy value of -36.49 kcal/mol. (Table-1 \& 2)

Whereas, Crystal ligand CKN (Pyrrolotriazine) has involved key interactions with residues forming $\mathrm{H}$-bond with Arg273(1.87), Arg273(2.88), Asn316(2.38), Asp329(2.48), Asp272(2.81), Asp272(2.37), and hydrophobic interactions with Met192, Val200, Lys213, Ala211, Val246, Met265, Leu318, residues with Libdock Score 130.28 and Cdock score 30.24 and binding energy value of $-82.79 \mathrm{kcal} / \mathrm{mol}$. It signifies that Coniferyl benzoate(12) is occupying the same residues of the active site of the crystal ligand. (Figure: $\mathbf{2} \& \mathbf{3}$ ). 


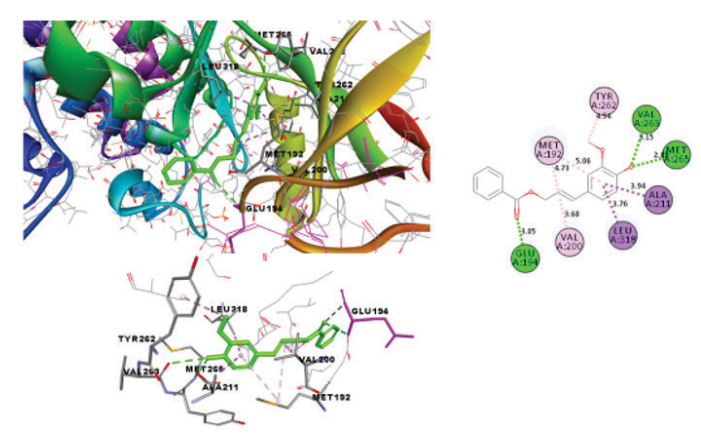

Figure 2: 3D and 2D Interactions of Coniferyl Benzoate 12 with 1RAK4 (PDB ID: 6F3I).

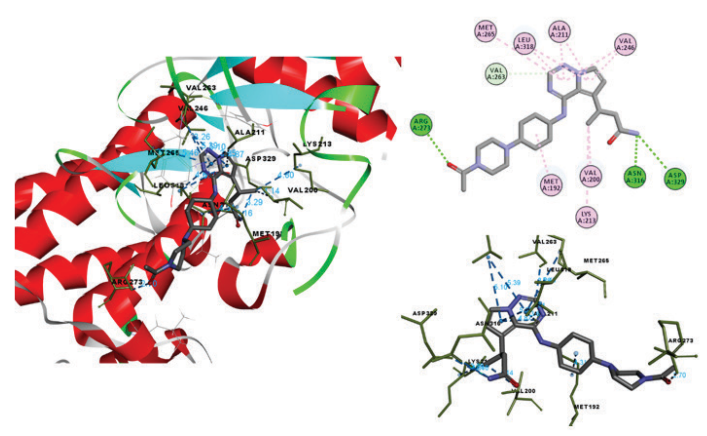

Figure 3: 3D and 2D Interactions of CKN with 1RAK4 (PDB ID: 6F3I).

\section{Molecular Docking Studies with NLRP3 inflam- masome (PDB ID: 6NPY):}

The molecular docking study was carried out for 22 phytoconstituents of Styrax Benzoin (1-22) into the active site of NLRP3 inflammasome (PDB ID: 6NPY). NLRP3 inflammatory signalling pathway plays a key role in the release of inflammatory mediators, on activation of NLRP 3 abrupt the cytochrome storms viz Interleukins (IL-1 $\beta$, IL-6) and TNFaand causes inflammatory in the lower respiratory tract. ${ }^{34}$ On the inhibition of NLRP3 will stop the release of negative inflammatory mediators.

Among the ligands docked against IRAK-4, coniferyl benzoate (12) has shown excellent free energy binding with Lib dock score 119.99and with Cdock score -27.54 and with a binding energy value of $-63.66 \mathrm{kcal} / \mathrm{mol}$. Coniferyl benzoate(12) exerted H-bond interactions and bond distance in $\AA$ with Thr167(2.22), Thr167(3.03), Arg165(2.40), Gly229(2.45), Gly227(2.95), amino acid residues and hydrophobic interactions with Phe371, Pro410, Ile232, Leu411, and Leu162 residues. Similarly, p-coumaryl cinnamate(6) has exhibited H-bond interactions with Thr167(1.98), His520(2.17), Thr167(2.02), Gly229(2.41) residues and hydrophobic interactions with Pro410, Ile232, Arg235 amino acid residues. (Table $1 \&$ 3)

Whereas, Crystal ligand CKN has involved key interactions with residues forming H-bond with His 163 and Glu166 with a bond distance of $2.06 \mathrm{~A}^{\circ}$ and $2.18 \mathrm{~A}^{\circ}$, respectively and hydrophobic interactions with His41, Met49 and Met165 residues. It signifies that p-coumaryl cinnamate(6) and Conifer$y l$ benzoate(12) is occupying the same residues of the active site of crystal ligand. (Figure: 4-6).

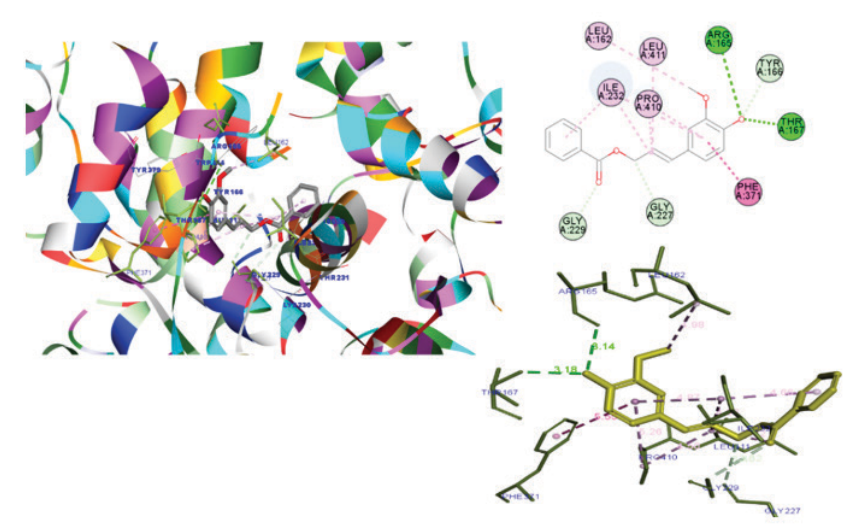

Figure 4: $3 D$ and 2D Interactions of Coniferyl Benzoate with NLRP3 (PDB ID: 6NPY).
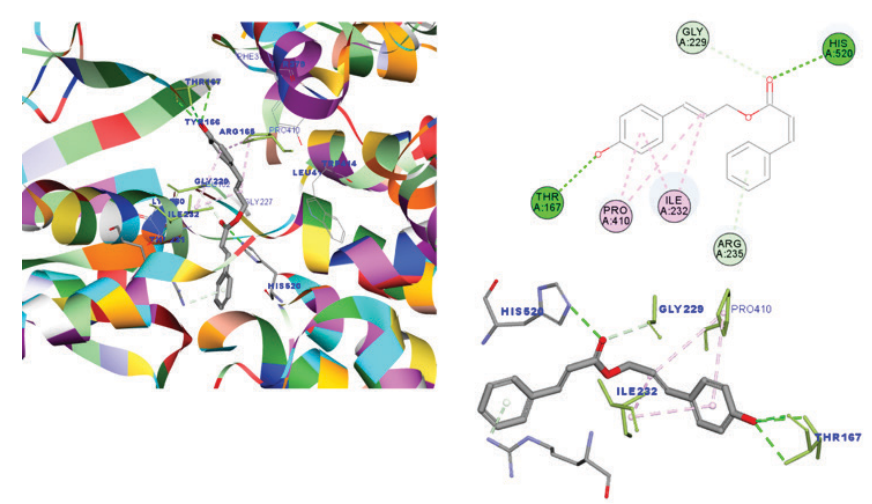

Figure 5: 3D and 2D Interactions of p-coumaryl cinnamate with NLRP3 (PDB ID : 6NPY).

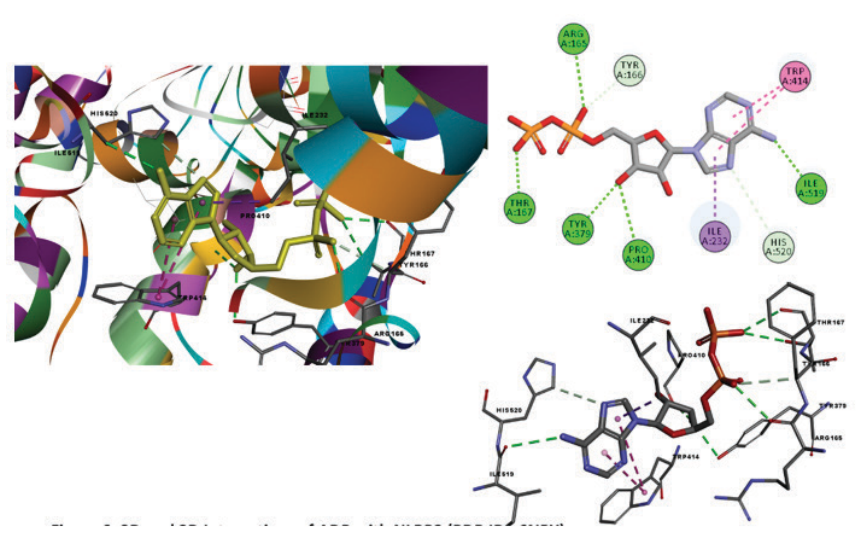

Figure 6: $3 D$ and $2 D$ Interactions of ADP with NLRP3 (PDB ID: 6NPY). 
Structure-Based Pharmacophore: The best protein-ligand pose of docking were further analysed for Pharmacophore features using Interaction Pharmacophore Generation Protocol. Table-4 give the details about Common Pharmacophore Feature for ligand p-coumaryl cinnamate $\mathbf{6}$ has HHDA pharmacophore feature and fit value 3.99 and rank 9.13 and whereas, coniferyl benzoate $\mathbf{1 2}$ has HHHDA pharmacophore features with fit value 4.99 and rank 11.50 which shows better features. The interaction pharmacophore features for receptor-ligand complex among the result coniferyl benzoate-6F3I complex has 10 pharmacophore models with $\mathrm{H}$ bond interactions Glu194, Val263, Tyr264, Met265 and with hydrophobic interactions Met192, Val200, Ala211, Tyr262, Leu318. Similarly, with coniferyl benzoate-6NPY complex has 10 pharmacophore models with H-bond interactions Arg165, Thr167, Gly227 and hydrophobic interactions Leu162, Ile232, Phe371, Pro410, Leu411. The interaction pharmacophore features are shown in Figure-7.

\begin{tabular}{|c|c|c|c|c|c|}
\hline $\begin{array}{l}\text { Compd } \\
\text { Id }\end{array}$ & $\begin{array}{l}\text { Phytochemical } \\
\text { Name }\end{array}$ & $\begin{array}{l}\text { Pharma- } \\
\text { cophore } \\
\text { features }\end{array}$ & $\begin{array}{c}\text { Fit } \\
\text { value }\end{array}$ & Rank & $\begin{array}{c}\text { Max } \\
\text { Fit }\end{array}$ \\
\hline 6 & $\begin{array}{l}\text { p-coumaryl cin- } \\
\text { namate }\end{array}$ & HHDA & 3.99 & 9.13 & 4 \\
\hline 12 & $\begin{array}{l}\text { Coniferyl Ben- } \\
\text { zoate }\end{array}$ & HHHDA & 4.99 & 11.50 & 5 \\
\hline
\end{tabular}

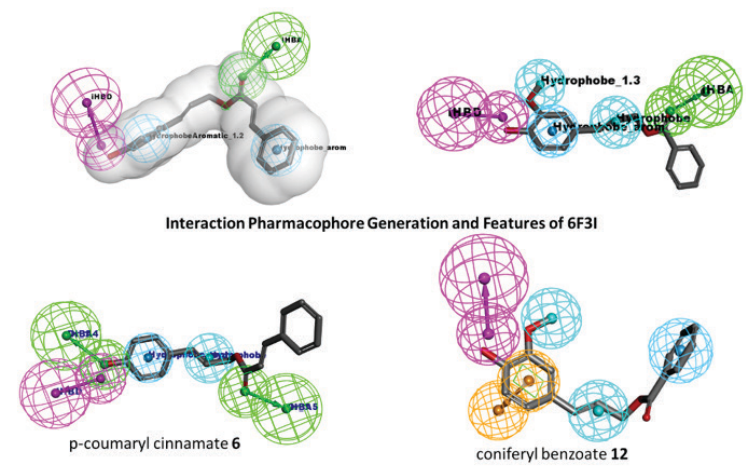

Figure 7: Interaction Pharmacophore Generation and Features of 6 NPY

\section{In Silico ADMET Prediction:}

In Silico Prediction of ADME and Toxicity parameters were analysed for the Phytoconstituents of Stryax Benzoin by using Discovery Studio, pKCSM webserver and Data Warrior Software. All the phytochemicals have obeyed Lipinski's rule of 5 in which the Mol. Wt is below $500, \log \mathrm{P}<5$, No of Hydrogen Bond Donors is $<5$ and Acceptors $<10$ and Molar refractivity (2) between 40-130. Almost all the phytochemicals have not deviated from the rule of 5 and hence they have the potential for oral absorption and less toxicity. (Figure-8).

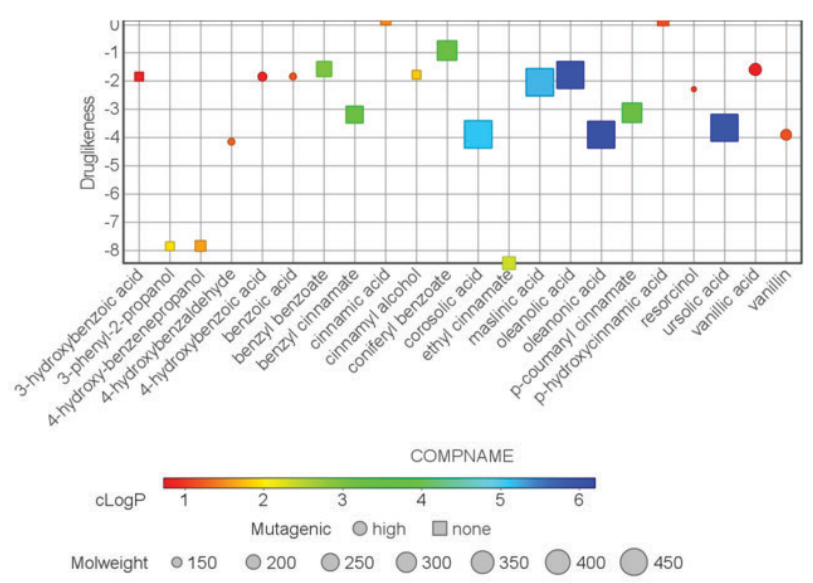

Figure 8: ADMET Properties of Phytochemicals of Styrax Benzoin.

Some of the potential Phytochemicals (1-7, 9, 11-16, 20) which have shown good binding affinity with the docking studies were analysed for ADMET using pKCSM webserver(Table-5). The absorption properties of the compounds are studied by Caco- 2 permeability, human intestinal absorption, skin permeability, and p-gp substrate or inhibitor. The predicted value $>0.90$ indicates high Caco- 2 permeability. Vanillin 1, vanillic acid 2, ursolic acid 3, resorcinol 4, p-OHcinnamic acid5, p-coumaryl cinnamate 6, oleanonic acid 7, masilinic acid9, corosolic acid 11, coniferyl benzoate12, cinnamyl alcohol13, cinnamic acid14, benzyl cinnamate15, benzyl benzoate16, 4-hydroxy-benzenepropanol20 were predicted to have high cacao-2 permeability. All phytochemicals have good intestinal absorption. In terms of skin permeability if the compounds have $\log \mathrm{Kp}>-2.5$ consider being low skin permeability. Among analysed compounds, cinnamyl alcohol13 was considering to have low skin permeability with $\log \mathrm{Kp}=-1.70$.

None of the phytochemicals is the substrate for p-glycoprotein which is an efflux transporter that excretes chemicals or drugs from the cells. All phytochemicals have the apparent volume of distribution the limits are VDss is low if log VDss $<-0.15$ and high if $\log$ VDss $>0.45$. For Blood-Brain Barrier permeability, compounds with $\log \mathrm{BB}>0.3$ consider crossing the $\mathrm{BBB}$ and $\log \mathrm{BB}<-1$ are impermeable to the brain. Phytoconstituents $12-16 \& 20$ will cross the BBB as predicted values are $\log B \mathrm{~B}>0.3$. Regarding CNS permeability, phytochemicals $6,7,9,11,13,14,15,16 \& 20$ have high CNS permeability (log PS $>-2$ ).

Cytochrome P450 is an important enzyme for the biotransformation of drugs in the liver and inhibitors of CYP450 will affect the pharmacokinetic properties of the drug. All phytochemicals are not substrate for CYP2D6, Compound 12, 13, 
Table 5: In Silico ADMET Predicted properties of Phytoconstitutents of Styrax Benzoin

\begin{tabular}{|c|c|c|c|c|c|c|c|c|c|c|c|c|c|c|c|}
\hline Properities & 1 & 2 & 3 & 4 & 5 & 6 & 7 & 9 & 11 & 12 & 13 & 14 & 15 & 16 & 20 \\
\hline \multicolumn{16}{|l|}{ Absorption } \\
\hline $\begin{array}{c}\text { Water solubility }(\log \\
\mathrm{mol} / \mathrm{L})\end{array}$ & -1.31 & -1.84 & -3.07 & -0.76 & -2.38 & -4.45 & -3.09 & -3.04 & -3.04 & -4.03 & -1.85 & -2.61 & -4.07 & -3.58 & -1.22 \\
\hline $\begin{array}{c}\text { Caco2 permeability } \\
(\log \text { Papp in } 10-6 \\
\mathrm{cm} / \mathrm{s})\end{array}$ & 1.22 & 0.33 & 1.17 & 1.68 & 1.21 & 1.37 & 1.28 & 0.63 & 0.64 & 1.33 & 1.61 & 1.72 & 1.60 & 1.43 & 1.69 \\
\hline $\begin{array}{c}\text { Intestinal absorption } \\
(\% \text { Absorbed })\end{array}$ & 84.98 & 78.15 & 100 & 86.86 & 93.49 & 91.23 & 100 & 100 & 100 & 90.88 & 92.67 & 94.83 & 95.79 & 95.84 & 81.82 \\
\hline $\begin{array}{c}\text { Skin Permeability } \\
(\log K p)\end{array}$ & -2.83 & -2.73 & -2.74 & -2.62 & -2.72 & -2.41 & -2.74 & -2.74 & -2.74 & -2.71 & -1.70 & -2.70 & -2.13 & -2.10 & -2.63 \\
\hline $\begin{array}{l}\text { P-glycoprotein } \\
\text { substrate }\end{array}$ & No & No & No & No & No & No & No & No & No & No & No & No & No & No & No \\
\hline $\begin{array}{l}\text { P-glycoprotein I } \\
\text { inhibitor }\end{array}$ & No & No & No & No & No & No & No & No & No & No & No & No & No & No & No \\
\hline $\begin{array}{l}\text { P-glycoprotein II } \\
\text { inhibitor }\end{array}$ & No & No & No & No & No & No & No & No & No & No & No & No & No & No & No \\
\hline \multicolumn{16}{|l|}{ Distribution } \\
\hline $\begin{array}{c}\text { VDss (human) (log } \\
\mathrm{L} / \mathrm{kg} \text { ) }\end{array}$ & -0.15 & -1.74 & -1.09 & -0.02 & -1.15 & -0.06 & -1.12 & -1.28 & -1.28 & -0.21 & 0.30 & -1.05 & 0.04 & -0.05 & 0.03 \\
\hline $\begin{array}{l}\text { Fraction unbound } \\
\text { (human) }\end{array}$ & 0.43 & 0.52 & 0.00 & 0.62 & 0.43 & 0.00 & 0.00 & 0.03 & 0.04 & 0.00 & 0.34 & 0.38 & 0.00 & 0.08 & 0.40 \\
\hline $\begin{array}{c}\text { BBB permeability } \\
(\log B B)\end{array}$ & -0.24 & -0.38 & -0.14 & -0.32 & -0.23 & 0.28 & -0.08 & -0.49 & -0.47 & 0.15 & 0.48 & 0.45 & 0.31 & 0.28 & -0.16 \\
\hline CNS permeability & -2.24 & -2.63 & -1.19 & -2.08 & -2.42 & -1.52 & -1.07 & -1.48 & -1.51 & -2.21 & -1.76 & -1.83 & -1.32 & -1.38 & -2.06 \\
\hline Metabolism & & & & & & & & & & & & & & & No \\
\hline CYP2D6 substrate & No & No & No & No & No & No & No & No & No & No & No & No & No & No & No \\
\hline CYP3A4 substrate & No & No & Yes & No & No & Yes & Yes & Yes & Yes & Yes & No & No & Yes & Yes & Yes \\
\hline CYP1A2 inhibitior & No & No & No & No & No & Yes & No & No & No & Yes & Yes & No & Yes & Yes & No \\
\hline CYP2C19 inhibitior & No & No & No & No & No & Yes & No & No & No & Yes & No & No & Yes & Yes & No \\
\hline CYP2C9 inhibitior & No & No & No & No & No & No & No & No & No & No & No & No & No & No & No \\
\hline CYP2D6 inhibitior & No & No & No & No & No & No & No & No & No & No & No & No & No & No & No \\
\hline CYP3A4 inhibitior & No & No & No & No & $\mathrm{No}$ & No & No & No & $\mathrm{No}$ & Yes & No & No & No & No & \\
\hline \multicolumn{16}{|l|}{ Excretion } \\
\hline $\begin{array}{c}\text { Total Clearance (log } \\
\mathrm{ml} / \mathrm{min} / \mathrm{kg})\end{array}$ & 0.60 & 0.63 & 0.08 & 0.24 & 0.66 & 0.66 & -0.13 & -0.07 & 0.09 & 0.56 & 0.25 & 0.78 & 0.76 & 0.73 & 0.29 \\
\hline $\begin{array}{l}\text { Renal OCT2 } \\
\text { substrate }\end{array}$ & No & No & No & No & No & No & No & No & No & No & No & No & No & No & No \\
\hline \multicolumn{16}{|l|}{ Toxicity } \\
\hline AMES toxicity & No & No & No & No & No & Yes & No & No & No & Yes & No & No & No & No & No \\
\hline hERG I inhibitor & No & No & No & No & No & No & No & No & No & No & No & No & No & No & No \\
\hline hERG II inhibitor & No & No & No & No & No & No & No & No & No & No & No & No & No & No & No \\
\hline $\begin{array}{l}\text { Oral Rat Acute } \\
\text { Toxicity (LD50) }\end{array}$ & 1.94 & 2.45 & 2.05 & 2.14 & 2.16 & 1.95 & 2.26 & 2.52 & 2.51 & 1.86 & 1.92 & 2.09 & 1.83 & 1.73 & 1.98 \\
\hline Hepatotoxicity & No & No & Yes & No & No & No & No & Yes & Yes & No & No & No & No & No & Yes \\
\hline Skin Sensitisation & No & No & No & Yes & No & No & No & No & No & No & Yes & No & $\overline{Y e s}$ & Yes & Yes \\
\hline T.Pyriformis toxicity & -0.01 & 0.27 & 0.29 & 0.11 & 0.32 & 1.19 & 0.29 & 0.29 & 0.29 & 1.02 & -0.13 & 0.25 & 1.66 & 1.36 & -0.08 \\
\hline Minnow toxicity & 1.90 & 1.93 & -0.79 & 2.19 & 1.61 & -0.62 & -1.22 & 0.24 & 0.28 & -0.15 & 1.87 & 1.72 & -0.54 & 0.83 & 1.90 \\
\hline
\end{tabular}

$16 \& 20$ are substrates for CYP3A4. Compounds 6, $12 \& 13$ are inhibitors for CYP1A2 inhibitors.

Regarding toxicity compound $\mathbf{6}$ has Ames toxicity, and compounds 3, 9, 11 have hepatoxicity, 4, 13, \& 20 has skin sensitisation problems. All phytochemicals have hERG toxicity and are free from cardiotoxicity. From these observations it could be revealed that all phytochemicals of Styrax Benzoin have shown good drug-like properties viz., no toxicity, good oral absorption, metabolism and excretion and no interaction with cytochrome P450 enzymes and free from cardiotoxicity.

\section{CONCLUSION}

In Silico computational studies like molecular docking, pharmacophore model, ADMET prediction could provide helpful information for the rapid design of drugs. Wound infection causes cytokine storms and releases negative inflammatory mediators such as 1RAK4 and NRLP3. Therefore, it could essential to find therapeutics for inhibiting the signalling pathways responsible for the release of negative inflammatory mediators. To find potent inhibitors for inflammatory targets 1RAK4 and NRLP3 inflammasome we performed molecular 
docking studies for 22 Phytoconstituents of Styrax Benzoin using Libdocker and $\mathrm{C}$ docker. The results have shown $\mathrm{p}-$ coumaryl benzoate $\mathbf{6}$ and coniferyl benzoate $\mathbf{1 2}$ have a high binding affinity against the protein targets. Detailed pharmacophore features were also generated against these docked complexes. ADMET prediction studies indicate that all the Phytoconstituents are having good oral absorption and less toxicity. The results suggest that the Phytoconstituents of Styrax Benzoin have the potential to be developed as novel inhibitors of inflammatory mediators. These inflammatory mediators are upregulated during SARS-CoV-2 infections. However, their clinical usage against inflammatory mediators is a subject of further investigations and clinical trials.

\section{Conflict of Interest: Nil}

\section{Source of Funding: Self}

\section{REFERENCES}

1. WHS 2019 Abstracts. Wound Repair and Regeneration. 2019;27(3): A1-A40.

2. Velnar T, Bailey T, Smrkolj V. The wound healing process: an overview of the cellular and molecular mechanisms. J. Int. Med. Res. 2009;37(5):1528-42.

3. Bertone AL. Principles of wound healing. Vet. Clin. North. Am. Equine. Pract. 1989 Dec 1;5(3):449-63.

4. George Broughton I, Janis JE, Attinger CE. The basic science of wound healing. Plast Reconstr Surg. 2006;117(7S):12S-34S.

5. Gillitzer R, Goebeler M. Chemokines in cutaneous wound healing. J. Leukoc. Biol. 2001;69(4):513-21.

6. Fara A, Mitrev Z, Rosalia RA, Assas BM. Cytokine storm and COVID-19: a chronicle of pro-inflammatory cytokines. Open. Biol. 2020;10(9):200160.

7. Bai B, Yang Y, Wang Q, Li M, Tian C, Liu Y, et al. NLRP3 inflammasome in endothelial dysfunction. Cell. Death. Dis.. 2020;11(9):1-18.

8. Werner S, Grose R. Regulation of wound healing by growth factors and cytokines. Physiol. Rev. 2003.

9. Fujiwara N, Kobayashi K. Macrophages in inflammation. Curr. Drug.Targ-Inflam Allergy. 2005;4(3):281-6.

10. Raja SK, Garcia MS, Isseroff RR. Wound re-epithelialization: modulating keratinocyte migration in wound healing. Front. Biosci. 2007;12(3):2849-68.

11. Baum CL, Arpey CJ. Normal cutaneous wound healing: clinical correlation with cellular and molecular events. Dermatologic surgery. 2005;31(6):674-86.

12. Weinheimer-Haus EM, Mirza RE, Koh TJ. Nod-like receptor protein-3 inflammasome plays an important role during the early stages of wound healing. PLoS One. 2015;10(3):e0119106.

13. Shen H-H, Yang Y-X, Meng X, Luo X-Y, Li X-M, Shuai Z-W, et al. NLRP3: a promising therapeutic target for autoimmune diseases. Autoimmun Rev. 2018;17(7):694-702.

14. Zhang X, Dai J, Li L, Chen H, Chai Y. NLRP3 inflammasome expression and signalling in human diabetic wounds and high glucose-induced macrophages. J Diabetes Res. 2017;2017.

15. Katsuyama E, Miyamoto H, Kobayashi T, Sato Y, Hao W, Kanagawa H, et al. Interleukin-1 receptor-associated kinase-4 (IRAK4) promotes inflammatory osteolysis by activating osteo- clasts and inhibiting the formation of foreign body giant cells. J.Bio.Chem. 2015;290(2):716-26.

16. Patra MC, Choi S. Recent progress in the molecular recognition and therapeutic importance of interleukin-1 receptor-associated kinase 4. Molecules. 2016;21(11):1529.

17. Borges T. Clinical Approach to Systemic Autoinflammatory Disorders: Classification, Disease Phenotypes and Management. Curr. Imm. Rev. 2018;14(2):105-19.

18. Zarrin AA, Bao K, Lupardus P, Vucic D. Kinase inhibition in autoimmunity and inflammation. Nat. Rev. Drug. Discov. 2020:125.

19. Sankaralingam R, Sengottuvelan B, Venkat P, Selvaraj M, Arunachalam V, Natarajan J. Experimental investigation on varying flame characteristics of benzoic resin solid fuel pellets. Renewable Energy. 2020;147:1500-10.

20. Saputra MH, Sagala SAH, Lee HS, editors. Species Distribution of Styrax sumatrana in North Sumatra using Maxent Modelling Approach. Forum Geografi; 2020.

21. Falzon CC, Balabanova A. Phytotherapy: An Introduction to Herbal Medicine. Prim Care. 2017 Jun;44(2):217-227.

22. Wang F, Zhang L, Zhang Q, Chen A, Wang S, Fang Z. Two new phenylpropanoids from the resin of Styrax tonkinensis (Pierre) Craib ex Hartw. J Nat Med. 2020:1-6.

23. Tra NT, Anh TD, Van Cuong P, Ha NTT, Anh LTT, Cham BT, et al. Chemical constituents from the leaves of Styrax annamensis Guill. Vietnam J Chem. 2020;58(5):630-6.

24. Nurwahyuni I, Situmorang M, Sinaga R. Plant Regeneration through Callus Cultures from Leaf Explant of Sumatra Benzoin (Styrax benzoin). Int J Forestry Res. 2020;2020.

25. Jaradat N. Phytochemistry, traditional uses and biological effects of the desert plant Styrax Officinalis L. J Arid Env. 2020;182:104253.

26. Atia Sharif HN, Rehman R, Mushtaq A, Rashid U. A review on the bioactive potential of Benzoin Resin. Int. J. of Chem. Biochem. Sci. 2016;10(1):106-10.

27. Du J, Singh H, Yi TH. Antibacterial, anti-biofilm and anticancer potentials of green synthesized silver nanoparticles using benzoin gum (Styrax benzoin) extract. Bioprocess Biosyst Eng. 2016;39(12):1923-1931.

28. Parkman C. Integrating CAM into traditional health care. The Case. Manager. 2000;11(3):27-9.

29. Degorce SL, Anjum R, Dillman KS, Drew L, Groombridge SD, Halsall CT, et al. Optimization of permeability in a series of pyrrolotriazine inhibitors of IRAK4. Bioorg Med Chem. 2018;26(4):913-24.

30. Sharif H, Wang L, Wang WL, Magupalli VG, Andreeva L, Qiao Q, et al. Structural mechanism for NEK7-licensed activation of NLRP3 inflammasome. Nature. 2019;570(7761):338-43.

31. Pires DEV, Blundell TL, Ascher DB. pkCSM: Predicting SmallMolecule Pharmacokinetic and Toxicity Properties Using Graph-Based Signatures. J Med Chem. 2015;58(9):4066-72.

32. Sander T, Freyss J, von Korff M, Rufener C. DataWarrior: An Open-Source Program For Chemistry Aware Data Visualization And Analysis. J Chem Inf Model. 2015;55(2):460-73.

33. Su L-C, Xu W-D, Huang A-F. IRAK family in inflammatory autoimmune diseases. Autoimmun. Rev. 2020;19(3):102461.

34. Sendler M, van den Brandt C, Glaubitz J, Wilden A, Golchert J, Weiss FU, et al. NLRP3 inflammasome regulates the development of systemic inflammatory response and compensatory anti-inflammatory response syndromes in mice with acute pancreatitis. Gastroenter. 2020;158(1):253-69. e14. 